Manuscript Number:

Title: Which chemicals should be grouped together with phthalates for mixture risk assessments of male reproductive disorders?

Article Type: SI: Endoc-Environment of ED

Keywords: Male reproductive health;

mixture risk assessment;

phthalates; anti-androgens; prostaglandin signalling

Corresponding Author: Andreas Kortenkamp,

Corresponding Author's Institution:

First Author: Andreas Kortenkamp

Order of Authors: Andreas Kortenkamp

Abstract: There is concern about cumulative exposures to compounds that disrupt male sexual differentiation in foetal life, leading to irreversible effects including declines in semen quality, testes nondescent, malformations of the penis and testis cancer. Traditional chemical-by-chemical risk assessment approaches cannot capture the likely cumulative health risks. However, past efforts of focusing on combinations of phthalates, a subgroup of chemicals suspected of contributing to these risks, also do not go far enough, as they ignore the contribution of other types of chemicals. With the aim of providing criteria for the inclusion of additional chemicals in mixture risks assessments for male reproductive health, we examine the mechanisms of action of various chemicals capable of disrupting male sexual differentiation. We construct an Adverse Outcome Pathway (AOP) network for malformations of the male reproductive system that includes new findings about the role of disrupting prostaglandin signalling. We use this network to identify pathways that converge at critical nodal points to produce down-stream adverse effects. From this knowledge we derive predictions of combinations of chemicals with different mechanisms of action that should result in cumulative effects. These predictions are then mapped against evidence from experimental mixture studies with relevant combinations. From the outcomes of these studies, we conclude that cumulative assessment groups for male reproductive health risks should not only include phthalates but also comprise androgen receptor (AR) antagonists, chemicals capable of disrupting steroid synthesis, InsL3 production, prostaglandin signalling and co-planar polychlorinated dibenzo-dioxins together with other dioxin-like compounds. This list goes far beyond what has been suggested previously. A minimum set of chemicals to be assessed together includes phthalates, pesticides such as vinclozolin, prochloraz, procymidone, linuron, pain killers including paracetamol, aspirin and ibuprofen, pharmaceuticals such as finasteride, ketoconazole, and the lipid-lowering drug simvastin, poly-chlorinated dibenzo-dioxins and other dioxin-like pollutants and phenolics such as bisphenol A and butylparaben. 



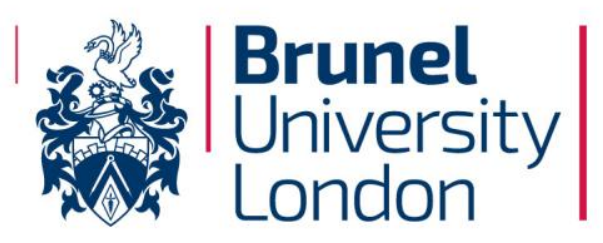

Dr Catherine Viguie
Institute of Environment, Health and Societies

Brunel University London

Kingston Lane

Uxbridge

UB8 3PH

United Kingdom

T +44 (0)1895 266525

E andreas.kortenkamp@brunel.ac.uk

www.brunel.ac.uk

Dear Catherine,

I have pleasure submitting an article entitled

Which chemicals should be grouped together with phthalates for mixture risk assessments of male reproductive disorders?

to the MCE special issue on environmental endocrine disruption.

With best wishes

Andreas 


\title{
1 Which chemicals should be grouped together with 2 phthalates for mixture risk assessments of male 3 reproductive disorders?
}

4

5

6

\author{
Andreas Kortenkamp \\ Brunel University London \\ Institute of Environment, Health and Societies \\ Kingston Lane \\ Uxbridge UB8 3PH \\ United Kingdom
}

Email: Andreas.kortenkamp@brunel.ac.uk

\section{Highlights}

- Adverse Outcome Pathway network for male reproductive malformations that includes the contribution of painkillers via disruption of prostaglandin signalling

- Nodal points in the network lead to overlapping adverse outcomes

- Empirical evidence of combination effects from activation of multiple pathways confirms the potential for cumulative effects involving diverse mechanisms

- Development of criteria for inclusion of chemicals in cumulative assessment groups for male reproductive health beyond phthalates

\begin{abstract}
There is concern about cumulative exposures to compounds that disrupt male sexual differentiation in foetal life, leading to irreversible effects including declines in semen quality, testes non-descent, malformations of the penis and testis cancer. Traditional chemical-by-chemical risk assessment approaches cannot capture the likely cumulative health risks. However, past efforts of focusing on combinations of phthalates, a subgroup of chemicals suspected of contributing to these risks, also do not go far enough, as they ignore the contribution of other types of chemicals. With the aim of providing criteria for the inclusion of additional chemicals in mixture risks assessments for male reproductive health, we examine the mechanisms of action of various chemicals capable of disrupting male sexual differentiation. We construct an Adverse Outcome Pathway (AOP) network for malformations of the male reproductive system that includes new findings about the role of disrupting prostaglandin signalling. We use this network to identify pathways that converge at critical nodal points to produce down-stream adverse effects. From this knowledge we derive predictions of combinations of chemicals with different mechanisms of action that should result in cumulative effects. These predictions are then mapped against evidence from experimental mixture studies with relevant combinations. From the outcomes of these studies, we conclude that cumulative assessment groups for male reproductive health risks should not only include phthalates but also comprise androgen receptor (AR) antagonists, chemicals capable of disrupting steroid synthesis, InsL3 production, prostaglandin signalling and co-planar polychlorinated dibenzo-dioxins together with other dioxin-like compounds. This list goes far beyond what has been suggested previously. A minimum set of chemicals to be assessed together includes phthalates, pesticides such as vinclozolin, prochloraz, procymidone, linuron, pain killers including paracetamol, aspirin and ibuprofen, pharmaceuticals such as finasteride, ketoconazole, and the lipid-lowering drug simvastin, polychlorinated dibenzo-dioxins and other dioxin-like pollutants and phenolics such as bisphenol A and butylparaben.
\end{abstract}




\section{Keywords}

2 Male reproductive health, mixture risk assessment, combined exposures, phthalates, anti-androgens,

3 prostaglandin signalling, azole pesticides, dioxins, bisphenol A, paracetamol

4

\section{Acknowledgements}

6 The work presented here was made possible partly with funding for the EU project CONTAMED

7 (FP7, grant 212502) and from the EU-funded HBM4EU project, all of which is gratefully 8 acknowledged. The author declares he has no conflicts of interest.

9 


\section{Introduction}

Several countries have experienced increases in testicular non-descent (cryptorchidisms, reviewed by Main et al. 2010) and penile malformations (hypospadias, Boisen et al. 2005; Nassar et al. 2007; Nelson et al. 2005; Pierik et al. 2002). The incidence of testicular germ cell cancers has risen steadily in Caucasian white men (Chia et al. 2010) while semen quality continues to decline (Levine et al. 2017). These disorders are part of a syndrome termed testicular dysgenesis syndrome (TDS), thought to arise from insufficient androgen action in foetal life (Skakkebaek et al. (2001). The TDS hypothesis predicts that exposures to chemicals capable of disrupting androgen signalling in foetal life, so-called anti-androgens, are an etiological factor.

Human biomonitoring studies have shown that multiple anti-androgens, including phthalates, phenolic substances, halogenated biphenyls and perfluorinated compounds are present in human tissues at the time when androgen signalling in foetal life is set up (reviewed by Mitro et al. 2015). Over the years, experimental evidence has accumulated that multiple anti-androgenic chemicals with diverse chemical characteristics can act together to disrupt androgen signalling and produce reproductive tract malformations. These experiments were conducted in a variety of test systems, including in vitro assays of androgen receptor activation (Ermler et al. 2011; Orton et al. 2012, 2014), in vivo studies of disruption of male sexual differentiation (Hass et al. 2007; Rider et al. 2008, 2010; Christiansen et al. 2009; Howdeshell et al. 2017; Conley et al. 2018) and ex vivo studies with human fetal testes (Gaudriault et al. 2017).

Taken together, these studies highlight the problems associated with human risk assessment approaches that focus on only one chemical at a time. A disregard for combined exposures is likely to significantly underestimate human health risks (Kortenkamp and Faust, 2018). Even approaches that consider multiple chemicals with similar chemical characteristics, such as phthalates, will fail to capture the full extent of risks (USNAS 2008). Accordingly, the US National Academy of Sciences recommended that human mixture risk assessments should not stop with phthalates but should include a multitude of other anti-androgenic chemicals (USNAS 2008). However, with one exception (Kortenkamp and Faust 2010), efforts of mixture risk assessment for anti-androgens have so far concentrated exclusively on phthalates (Beko et al. 2013; Dewalque et al. 2014; Kranich et al. 2014; Hartmann et al. 2015; Chang et al. 2017; Dong et al. 2018; Du et al. 2018) and ignored other chemicals that can also disrupt androgen signalling in fetal life. Partly, this is due to a lack of clarity which other chemicals to group together with phthalates for mixture risk assessments. In addition, there are issues of limited data availability (Kortenkamp and Faust 2010). To perform such assessments, exposure data and potency estimates must be available, and this condition is not fulfilled for many anti-androgenic substances.

There is also confusion about the scientific principles that should underpin the grouping of phthalates with other chemicals in mixture risk assessments. It is often held that substances that do not share a common mode or mechanism of action are unlikely to produce combined toxicity. In current US EPA guidance (USEPA 2002) only chemicals that have a common mechanism are expected to contribute to mixture risks and are therefore grouped together for mixture risk assessment. Often, these mechanisms are so narrowly defined that only substances with the same chemical structural features are left for grouping, leading to the exclusion from the mixture risk assessment process many substances with other features and other modes of action. USEPA currently keeps organophosphates and carbamates in separate cumulative assessment groups, although both groups of chemicals exhibit neurotoxicity by inhibition of acetyl-cholinesterase.

The question of grouping phthalates with other anti-androgenic agents has acquired added urgency with the recent discovery of the role of analgesics in disrupting male sexual differentiation (Kristensen et al. 2011a, b, 2016; Snyder et al. 2012; Kugathas et al. 2016). These chemicals act via pathways that do not involve interaction with the androgen receptor (AR). Should they be assessed jointly with phthalates to estimate risks to male reproductive health?

In this paper, we briefly recapitulate the theoretical foundations of mixture assessment concepts and their relation to considerations of modes of action or mechanisms. We then consider an Adverse 
Outcome Pathway (AOP) network for disruption of male sexual differentiation and whether it can be used to derive criteria for groups of anti-androgens with diverse chemical structures and modes of action expected to affect common adverse outcomes. We map the leads that emerge from these considerations against the experimental evidence from mixture studies with anti-androgenic and other chemicals. Finally, we propose groups of chemicals that should be subjected to human mixture risk assessment to protect from co-incidental exposures to phthalates and other chemicals able to disrupt male sexual development.

\section{Theoretical foundations of concepts for the assessment of combined toxicity}

Mixture toxicology has developed a predictive orientation, based on the discovery that the combined effects of chemicals will be "additive" if all components exert their effects without interfering with the toxicity of other components. This opened ways of predicting combination effects based on the toxicity of chemicals in the mixture. It also provided the foundations for defining synergisms and antagonisms: synergistic effects exceed, and antagonistic effects fall short of the calculated additivity. The additivity expectations needed for such assessments can be derived by using two alternative concepts, dose addition (DA) and independent action (IA). The widely used toxicity equivalency factor approach is an application of the principles of DA. These concepts allow the quantitative prediction of combined effects when quantitative measures of each individual component's toxicity are available. It has become common to reference combined effects of chemicals in terms of the similarity or dissimilarity of their modes of action, first introduced by Bliss (1939) and Hewlett and Plackett (1952) on the basis of statistical principles.

Similar action is allied to the mixture assessment concept of DA, while dissimilar action in linked to IA. Although the original paper by Loewe and Muischneck (1926) that developed the DA concept contains little that roots it in mechanistic considerations, the link to similar modes of action of all mixture components probably derives from the "dilution" principle which forms the basis of DA. DA views chemicals as dilutions of each other, whereby each chemical can be replaced with an equieffective fraction of another, without loss of combination effect. It is assumed that this is only possible if all chemicals in the mixture act via a common or similar mechanism.

Conversely, IA is widely held to be appropriate for mixtures of agents with diverse or "dissimilar" modes of action. Although rarely stated explicitly, this stems from the stochastic principles that underpin this concept. The idea that chemicals act independently is equated with the notion of action through different mechanisms. By activating differing effector chains, so the argument, every component of a mixture of dissimilarly acting chemicals provokes effects independent of all other agents that might also be present. However, theoretically, the stochastic principles of IA are also valid when one and the same agent is administered sequentially and when irreversible events such as mortality are investigated. Because organisms cannot die twice, probabilistic principles apply, even though the precise mechanisms that underlie the toxic action of the chemical are identical. Only in the case of simultaneous administration of many chemicals can the principle of independent events be realised with strictly independent, dissimilar mechanisms.

Accordingly, there is a consensus among human toxicologists that similar action "occurs when chemicals in a mixture act in the same way, by the same mechanism/mode of action, and differ only in their potencies" (EFSA 2008). Conversely, "dissimilar action" is said to apply to combinations of chemicals that produce a common effect by action through different modes of action, or at different sites (EFSA 2008).

While these definitions may appear clear-cut, distinguishing between dissimilar action and similar action is often difficult to achieve in practice. In many cases, the mechanistic information needed to differentiate between the two ideas is not available. Clear decisions are further complicated by ambiguities in the precise meaning of the terms "mode of action", "mechanism" and "site of action" and how these should be applied during assessments of combination effects. These issues have relevance when it comes to decisions about which chemicals to include in mixture risk assessments for impacts on male reproductive health. For example, two chemicals might affect different pathways leading to a common adverse outcome, such as combinations of phthalates and 2,3,7,8 TCDD. Both chemicals are capable of reducing sperm numbers after exposure during gestation, but through 
different pathways and mechanisms (Gray et al. 1995; Foster et al. 2010). Can a joint effect be expected after combined exposures? Proponents of common mechanism groups based on strict similarity of action would deny such a possibility and consider the grouping of phthalates and TCDD in mixture risk assessment as inappropriate.

\section{Adverse outcome pathway (AOP) networks relevant to the induction of male reproductive malformations}

In this section we will recapitulate what is known about the mechanisms of anti-androgenic chemicals and construct an AOP network for male reproductive malformations, with a view of developing criteria for the grouping of phthalates and other anti-androgens in mixture risk assessment. The pathways relevant to what has been called the "AR antagonist", "phthalate", "dioxin" and "prostaglandin syndromes" are summarised in the AOP network depicted in Figure 1, a modified and extended version of a scheme developed by Howdeshell et al. (2016).

The androgens testosterone (T) and dihydrotestosterone (DHT) are required for the proper development of the male reproductive tract. T stimulates the differentiation of the Wolffian ducts into epididymis, vas deferens and seminal vesicles, the growth of the leviator anus muscle and the development of testes. DHT, which is produced in local tissues through conversion of T by 5 -alpha reductase, stimulates the differentiation and development of the genital tubercle into the penis, and the development of the prostate. The growth of the gubernacular cords which are essential for testicular descent is stimulated by InsL3, a peptide hormone secreted by the Leydig cells in the testes. The final phase of testes descent into the scrotal sack is dependent on androgens.

Figure 1: AOP network for the induction of male reproductive malformations (modified and extended from Howdeshell et al. 2017). Cells shaded red depict pathways for AR antagonism and down-regulation of steroidogenic enzymes, yellow cells are for the InsL3-mediated pathway leading to cryptorchidism and cells coloured blue highlight the prostaglandin-mediated pathways. Cells in cobalt blue are for the dioxin-induced pathway leading to poor sperm counts.

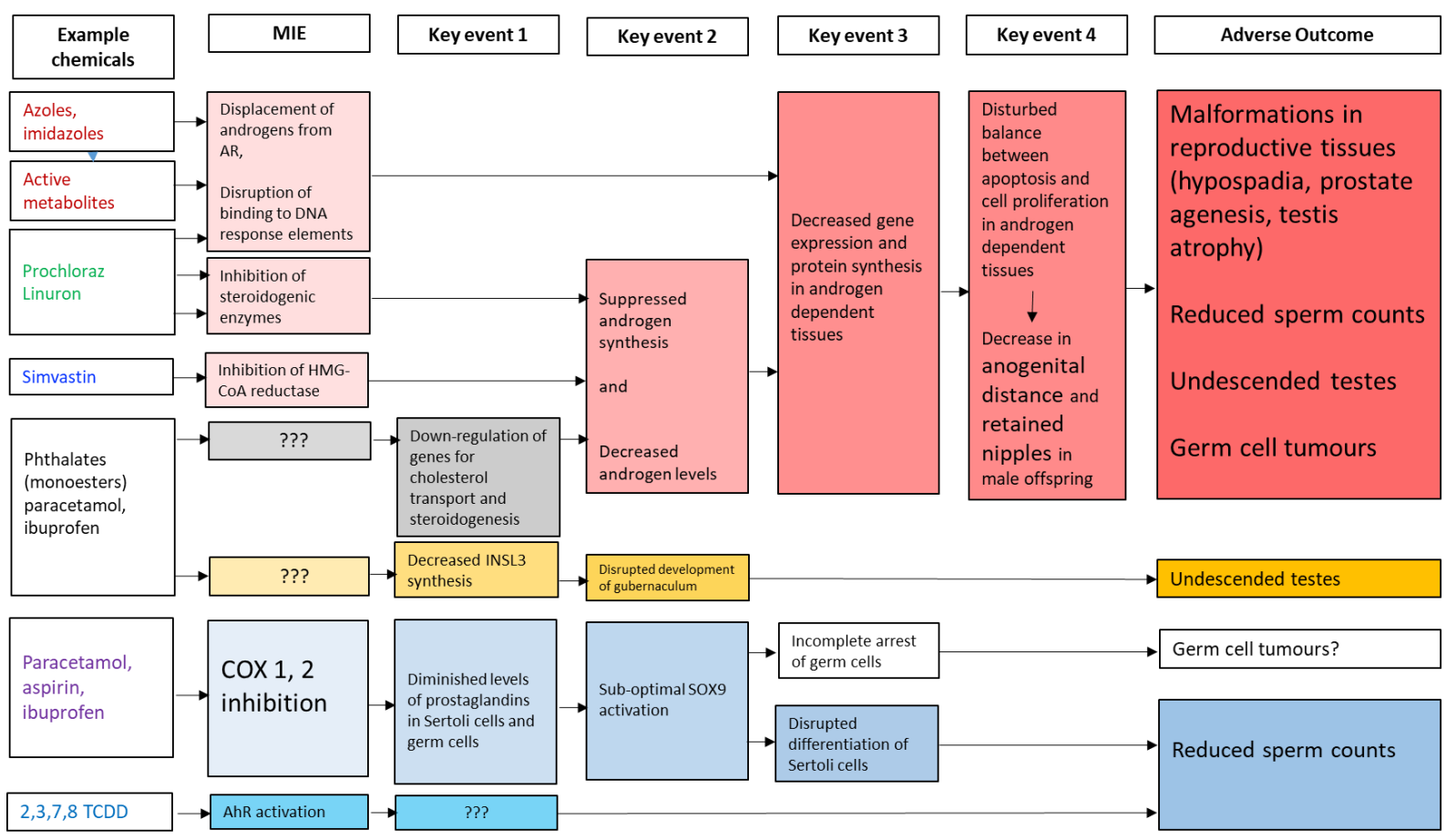

In the rat, the development and differentiation of the male reproductive tract can be disrupted in many ways. Interference with the action of T, e.g. by antagonising the androgen receptor (AR), or by supressing T synthesis, will affect the seminal vesicles, epididymis, vas deferens and testis. Blocking of DHT action tends to compromise prostate and penis development, leading to prostate agenesis and 
malformations of the penis (hypospadias), and a shortening of the anogenital distance (AGD). Because DHT is also required for the regression of nipple anlagen in the developing male rat, disruption of DHT action leads to retained nipples and areolas in male offspring.

Through careful examination of the effect patterns seen with different chemicals, Wolf et al. (1999) were able to elaborate several "syndromes" of reproductive tract malformations, including the "AR antagonist syndrome", the "phthalate syndrome" and what might be called the "dioxin syndrome". In the light of more recent evidence about the role of prostaglandin signalling in male sexual differentiation (reviewed by Kristensen et al. 2016) a "prostaglandin syndrome" should also be considered. The responses and adverse outcomes that characterise each of these syndromes overlap with each other.

The distinguishing pattern of the "AR antagonist syndrome" (Gray et al. 2004) is determined by the displacement of T and DHT from the AR by receptor antagonists, which is the molecular initiating event (MIE) of this adverse outcome pathway (Figure 1). Once occupied by an antagonist, the receptor cannot bind to its DNA response elements and fails to initiate transcription of androgen specific genes. Decreased gene expression and protein synthesis in all androgen dependent tissues are the consequence (key event 3 in Figure 1). At the tissue level, the balance between cell proliferation and apoptosis is disturbed (key event 4), leading to a pattern of malformations characterised by hypospadias, testes non-descent (cryptorchidism), epididymal lesions, severe prostate lesions including agenesis, and reduced sperm production. In the rat, shortened AGD and retained nipples are characteristic AR antagonist effects. Chemicals shown to produce the "AR antagonist syndrome" include the drug flutamide, and the dicarboximide pesticides vinclozolin and procymidone. Recently, butylparaben, an estrogenic agent that also has in vitro AR antagonist properties (Ermler et al. 2011), was shown to induce shortened AGD, reduced epididymal sperm counts and diminished ventral prostate weights in male rats exposed during gestation (Boberg et al. 2016). Similarly, bisphenol A, another in vitro AR antagonist (Ermler et al. 2011) exhibited a mild form of AR antagonist responses in the rat, limited to changes in AGD and retained nipples, but without weight changes in sex accessory glands and organs (Christiansen et al. 2014). Inhibition of 5-alpha reductase (MIE) by finasteride induces an effect spectrum very similar to AR antagonists, but with lower incidences of hypospadias and cryptorchidism. There are no effects on the vas deferens or the epididymis, and the severe retardations of prostate development characteristic of AR antagonists do not materialise (Imperato-McGinley et al. 1992). It appears that $\mathrm{T}-$ still available and active in finasteride-exposed rodents as the drug has little AR antagonistic properties - can to a degree compensate for the loss of DHT through 5-alpha reductase inhibition.

In contrast, phthalates affect the developmental of external genitalia and prostate to a smaller degree and instead produce an effect pattern characterised by testes and epididymis agenesis, combined with often complete agenesis of the gubernacular cords, all adverse outcomes rarely seen in the "AR antagonist syndrome" (Wolf et al. 1999; Gray et al. 2004). This effect spectrum ("phthalate syndrome") derives from the ability of phthalates to suppress InsL3 peptide hormone production and $\mathrm{T}$ synthesis in fetal Leydig cells (key event 1; the MIEs for these pathways are unclear). Without InsL3, the gubernacular cord cannot develop properly (key event 2), leading to disruptions of testis descent and finally cryptorchidism. Phthalates also down-regulate genes involved in the transport of cholesterol, a precursor required for androgen synthesis, and several steroidogenic enzymes. The resulting diminished $\mathrm{T}$ levels (key event 2 ) in foetal Leydig cells alter their developmental trajectory such that they continue to proliferate but fail to differentiate properly. As a result, Leydig cells in phthalate exposed foetal testes typically appear in large clusters, usually not seen with AR antagonists. The suppressed testicular T levels also result in reduced sperm numbers and have knockon effects on DHT levels. Accordingly, reduced (feminised) AGD and retained nipples (key event 4) are observed in male rats exposed to phthalates in foetal life. However, phthalates do not interact with the AR. Instead, they down-regulate genes for cholesterol transporters and steroidogenesis (key event 1) by mechanisms yet poorly understood. 
The phenyl urea herbicide linuron, despite being a weak AR antagonist, exhibits a pattern not typically seen with AR antagonists. It produces an unexpectedly high degree of epididymal malformations and testes lesions, a spectrum more in line with the "phthalate syndrome" (Wolf et al. 1999). This may be related to its ability to directly inhibit steroidogenic enzymes (MIE), thus leading to diminished levels of androgens (key event 2) (Wilson et al. 2009). Similarly, the fungicide prochloraz displays AR antagonistic properties and directly inhibits steroidogenic enzymes (MIE) with diminished testicular and serum $\mathrm{T}$ as the consequence. It produces an effect spectrum similar to AR antagonists and agents capable of driving down T synthesis (Laier et al. 2007).

Recently, inhibition of 3-hydroxy-3-methyl-glutaryl coenzyme A reductase (HMG-CoA reductase) by simvastin, a lipid-lowering drug, was also shown to affect male sexual differentiation. HMG-CoA reductase controls the rate-limiting step in cholesterol synthesis. As cholesterol is an essential precursor in steroid synthesis, inhibition of that enzyme can be expected to compromise $\mathrm{T}$ synthesis in foetal testes. Beverly et al. $(2014,2019)$ showed that this is indeed the case. The lowered T levels in foetal testes had knock-on effects on androgen action in terms of shortened AGD, retained nipples, disrupted testes development and reduced weights of seminal vesicles and leviator anus muscle (Beverly et al. 2019).

Co-planar polychlorinated biphenyls (PCB) and polychlorinated dibenzo-dioxins (PCDD) fall into an entirely different category ("dioxin syndrome"). Although there are clear disruptions of male sexual differentiation characterised by reduced sperm numbers, altered AGD and interferences with the development of seminal vesicles and prostate (Gray et al. 1995; Wolf et al. 1999), 2,3,7,8 TCDD and PCB 169 act through mechanisms not involving the androgen hormone system as they do not interfere with the AR. The decreases in T levels that were sometimes, but not always, observed (Foster et al. 2010), cannot explain the low sperm numbers characteristic of PCB 169- and 2,3,7,8 TCDD-exposure in foetal life. The mode of action of these substances in reducing sperm counts remains unclear, and whether these effects are mediated through AhR activation is not resolved. Disruption of epididymal function is discussed as one possibility (Foster et al. 2010). In the brain of gestationally exposed rats, 2,3,7,8 TCDD suppresses the expression of glutamic acid decarboxylase 67, an enzyme involved in GABA synthesis. This may prevent the perinatal surges of luteinising hormone and $\mathrm{T}$ and thus compromise sperm counts (EFSA 2018).

The possibility that disruption of male reproductive development might also occur through suppression of prostaglandin signalling was pointed out as early as the 1980s, when Gupta and colleagues presented evidence that prostaglandins play a role in the folding and fusion of the penis and scrotum during sexual development in mice (Gupta and Goldman 1986, Gupta and Bentlejewski 1992). However, few studies had examined prostaglandin signalling as a target for reproductive tract malformations, until Kristensen and colleagues (Kristensen et al. $2011 \mathrm{a} \mathrm{b}$ ) demonstrated that phenolic compounds (phthalates, benzophenones, parabens and alkyl phenols) and a variety of analgesics (paracetamol / acetaminophen, aspirin, ibuprofen, indomethacin) were capable of suppressing PGD2 and PGE2 synthesis in a mouse Sertoli cell line (SC5 cells), human mast cells and in ex vivo isolated rat testes. Inhibition of COX enzymes (MIE) was highlighted as the likely mode of action for these effects. We were able to show that an unexpected variety of chemicals with diverse chemical structural features, including several pesticides, are also capable of triggering this pathway (Kugathas et al. 2016).

Prostaglandins have a role in providing a back-up mechanism for supporting the expression of the Sox9 gene (SRY box containing gene 9) which is stimulated by Sry (sex-determining region on chromosome Y) (Adams and McLaren 2002; Wilhelm et al. 2007; Moniot et al. 2009). Sox9 drives the differentiation of Sertoli cells in the genital ridge. Sry and Sox9 up-regulate prostaglandin D2 synthase thereby promoting prostaglandin D2 (PGD2) synthesis and secretion. In turn, PGD2 acts via its DP receptor to upregulate Sox9 expression. This PGD2 back-up mechanism ensures that cells which have failed to reach a critical threshold of Sry expression can still be induced to up-regulate Sox9 and subsequently differentiate into Sertoli cells (reviewed by Koopman 2010). Exposures that suppress PGD2 synthesis can therefore be expected to disrupt this back-up mechanism. The 
importance of prostaglandin signalling for normal testis descent came to light with the demonstration that mutant mice with PGD2 synthase knock-outs exhibited unilateral cryptorchidism (Philibert et al. 2013).

Evidence from experimental studies with rats shows that paracetamol exposure in foetal life induces shortened AGD (Kristensen et al. 2011; Holm et al. 2015; van den Driesche et al. 2015) and retained nipples (Axelstad et al. 2014) in male offspring, yet paracetamol does not interact with the AR (Ermler, Kortenkamp unpublished observations). Reminiscent of the patterns seen with phthalates, paracetamol suppresses T synthesis (key event 2) (Kristensen et al. 2011, van den Driesche et al. 2015), probably due to its ability to down-regulate several steroidogenic enzymes (CYP 11a1, 17a1; key event 1) (van den Driesche et al. 2015). Paracetamol also inhibits COX enzymes (MIE) and accordingly, suppresses prostaglandin D2 production in the rat (key event 1; Kristensen et al. 2011a). In ex vivo isolated human foetal testes cultures, paracetamol induced suppressions of prostaglandin $\mathrm{E}$ and the peptide hormone InsL3 (key event 1; Mazaud-Guittod et al. 2013). Several epidemiological studies have shown that the use of paracetamol towards the end of the first trimester and early in the second trimester (the proposed window of sexual differentiation in humans) is associated with an increased risk of cryptorchidism (Berkowitz and Lapinski 1996, Jensen et al. 2010, Kristensen et al. 2011a, Philippat et al. 2012, Snijder et al. 2012, Lind et al. 2013). More recently, Fisher et al. (2016) were able to demonstrate associations also with feminised AGD in humans. Due to its ability to suppress both InsL3 and prostaglandins - factors important in ensuring proper testis descent - it is difficult to distinguish the relative importance of these two pathways in paracetamol-induced cryptorchidisms.

\section{Developing criteria for cumulative assessment groups - mechanistic thinking or pathway considerations?}

Of relevance to mixture risk assessment and the development of criteria for grouping chemicals into cumulative assessment groups, several points can be highlighted:

First, one and the same chemical may trigger more than one pathway. As discussed above, examples are linuron and prochloraz, both AR antagonists which are also capable of inhibiting steroidogenic enzymes leading to diminished androgen levels. Another example is paracetamol, which can disrupt prostaglandin signalling, depress InsL3 synthesis and down-regulate steroidogenic enzymes. By application of criteria of strict similarity of action it can be expected that combination effects arise from substances that trigger exactly the same set of pathways (here: prochloraz and linuron), but not from combinations that only share some MIEs and their corresponding pathways. Thus, the use of strict similarity of action as a grouping criterion might lead to rather small cumulative assessment groups as it becomes increasingly unlikely to find matching sets of chemicals with the same mechanisms as the number of MIEs increases.

In contrast, AOP thinking leads to the expectation that independent effector chains can converge and trigger cumulative effects further down-stream, especially when there are overlaps in the effect patterns of several pathways, and when pathways starting with different MIEs converge at nodal points in the network to produce common adverse outcomes (see Figure 1). An example are the reductions in sperm numbers seen with AR antagonists, phthalates and dioxins, which can be traced back to several distinct MIEs and key events, including AR antagonism, suppression of T synthesis and other as yet unidentified MIEs. Similarly with cryptorchidisms: These can be produced by agents that suppress InsL3 expression, T synthesis and prostaglandin signalling such as phthalates and paracetamol. Accordingly, activation of these pathways starting from different MIEs should also lead to cumulative effects with respect to cryptorchidisms.

Thus, distinctions between similarity and dissimilarity of action that have become established in mixture toxicology are not helpful in anticipating the potential for cumulative effects, and grouping criteria derived from a narrow mechanistic perspective may overlook important contributors to joint effects. Rather, mechanistic considerations should be enriched by AOP thinking and this may help to 
resolve the ambiguities that stem from the concepts of similar and dissimilar action. In the following section we will assess the usefulness of this idea by evaluating the empirical evidence for cumulative effects from converging pathways relevant to disruption of male sexual development.

\section{Cumulative effects from converging and interacting pathways leading to male reproductive malformations and disorders: evidence from experimental studies}

Empirical evaluations of the idea that joint adverse reproductive tract effects may arise from exposure to chemicals that trigger different MIE (Figure 1) require complex systems where responses from different effector chains can materialise at the appropriate level of biological complexity (tissue, organ or organism). Experiments involving cell-based assays (e.g. AR activation assays with reporter genes) can usually not capture such effects and must therefore be excluded from consideration here. The same applies to experiments that have used mixtures of chemicals with similar mechanisms of action, such as combinations of AR antagonists (Hass et al. 2007) or phthalates (Howdeshell et al. 2008).

A second requirement is that a minimum of relevant mechanistic information must be available for the chemicals included in mixtures. We therefore have to disregard studies where chemicals with a common effect, but insufficient mechanistic characterisation were combined, such as in our experiments with substances capable of suppressing $\mathrm{T}$ synthesis in ex vivo isolated human foetal testes (Gaudriault et al. 2017).

Third, several whole mixture studies that have modelled environmental human exposures or low-level exposures with quite large numbers of components (Christiansen et al. 2012; Isling et al. 2014; Conley et al. 2018) are not informative for our purposes here, because the effects of single chemicals were not recorded. This makes it difficult to attribute the combined effect to specific chemicals with distinct mechanisms of action.

Finally, due to the developmental origin of the adverse outcomes examined here, only studies where exposure covered the male programming window (gestational days 14-18 in the rat, Sharpe et al. 2006) are eligible here. Experiments with adult animals are excluded from consideration.

Relevant information is accessible from studies where expected mixture effects were calculated based on information about the potency of all mixture components. Also useful are studies where at least some mixture components were tested singly, as this allows us to glean something about the contribution of such components to the combined effect. We located 9 studies that meet the above requirements. Arranged according to the number of mixture components, these studies are listed in Table 1, together with information about the selected chemicals, the endpoints evaluated and agreement (or otherwise) with the effects predicted by the additivity concepts of DA and IA. Unless stated otherwise, pregnant rats (Long Evans, Sprague-Dawley or Wistar strains) were exposed to the mixtures during the male programming window and their male offspring examined for signs of disrupted sexual differentiation and reproductive malformations.

A mixture of butyl-benzyl phthalate (BBP) and linuron led to decreases in T production and caused malformations in androgen-dependent tissues (Hotchkiss et al. 2004). The degree of diminished $T$ production seen with the mixture was greater than that observed with BBP or linuron singly. This was also the case when shortened AGD and retained nipples were examined. At the doses tested, neither BBP nor linuron alone induced external genital malformations such as cleft prepuce, cleft phallus or hypospadias, however, these effects occurred in more than half of the animals exposed to the combination. The incidence of malformations of the prostate (agenesis) and epididymis (agenesis) was greater with the mixture than with either chemical individually. While it is not possible to examine these responses in terms of agreement with additive mixture effects, because dose-response information for BBP and linuron was not provided, it can be concluded that the two agents worked together to produce joint effects. Initiated via different MIEs or key events (linuron: AR antagonism, direct inhibition of enzymes responsible for T production; BBP: down-regulation of expression of 
steroidogenic genes), the respective AOPs converged at the level of decreased gene expression and protein synthesis in androgen-dependent tissues (key event 3, Figure 1) where they cumulated to produce adverse outcomes.

4 Table 1: List of mixture experiments with chemicals that disrupt male sexual differentiation 5 through different mechanisms of action

\begin{tabular}{|c|c|c|c|}
\hline Mixture composition & Endpoints examined & $\begin{array}{l}\text { Assessment of } \\
\text { observed combined } \\
\text { effect }\end{array}$ & Reference \\
\hline $\mathrm{BBP}$, linuron & $\begin{array}{l}\text { Suppression of T synthesis, } \\
\text { hypospadias, internal } \\
\text { malformations (prostate, } \\
\text { epididymis etc.) }\end{array}$ & $\begin{array}{l}\text { Combined effects larger } \\
\text { than those of single } \\
\text { chemicals }\end{array}$ & Hotchkiss et al. 2004 \\
\hline \multirow[t]{5}{*}{ DBP, procymidone } & Shortened AGD & $\begin{array}{l}\text { Agreement with DA and IA } \\
\text { predictions }\end{array}$ & \multirow[t]{5}{*}{ Hotchkiss et al. 2010} \\
\hline & Retained nipples & $\begin{array}{l}\text { Agreement with DA and IA } \\
\text { predictions }\end{array}$ & \\
\hline & Hypospadias & $\begin{array}{l}\text { Agreement with DA and IA } \\
\text { predictions }\end{array}$ & \\
\hline & Reduced ventral prostate & $\begin{array}{l}\text { Agreement with DA and IA } \\
\text { predictions }\end{array}$ & \\
\hline & Epididymal agenesis & $\begin{array}{l}\text { Agreement with DA and IA } \\
\text { predictions }\end{array}$ & \\
\hline DPP, simvastin & Suppression of T synthesis & $\begin{array}{l}\text { Combined effects larger } \\
\text { than those of single } \\
\text { chemicals }\end{array}$ & Beverly et al. 2014 \\
\hline \multirow[t]{8}{*}{$2,3,7,8$ TCDD, DBP } & $\begin{array}{l}\text { Reduced epididymal sperm } \\
\text { numbers }\end{array}$ & $\begin{array}{l}\text { Larger than effect } \\
\text { summation }\end{array}$ & \multirow[t]{8}{*}{ Rider et al. 2010} \\
\hline & Reduced epididymal weight & $\begin{array}{l}\text { Larger than effect } \\
\text { summation }\end{array}$ & \\
\hline & $\begin{array}{l}\text { Epididymal and testicular } \\
\text { malformations }\end{array}$ & $\begin{array}{l}\text { Larger than effect } \\
\text { summation; TCDD } \\
\text { exacerbates effect of DBP }\end{array}$ & \\
\hline & $\begin{array}{l}\text { Malformed external } \\
\text { genitalia (hypospadias) }\end{array}$ & $\begin{array}{l}\text { Larger than effect } \\
\text { summation }\end{array}$ & \\
\hline & Retained nipples & $\begin{array}{l}\text { Agreement with DA and IA } \\
\text { predictions }\end{array}$ & \\
\hline & Hypospadias & $\begin{array}{l}\text { Agreement with DA and IA } \\
\text { predictions }\end{array}$ & \\
\hline & Reduced ventral prostate & $\begin{array}{l}\text { Agreement with DA and IA } \\
\text { predictions }\end{array}$ & \\
\hline & Epididymal agenesis & $\begin{array}{l}\text { Agreement with DA and IA } \\
\text { predictions }\end{array}$ & \\
\hline
\end{tabular}




\begin{tabular}{|c|c|c|c|}
\hline \multirow[t]{4}{*}{$\begin{array}{l}\text { DEHP, vinclozolin, } \\
\text { finasteride, prochloraz }\end{array}$} & Shortened AGD & $\begin{array}{l}\text { Agreement with DA } \\
\text { prediction }\end{array}$ & \multirow[t]{4}{*}{ Christiansen et al. 2009} \\
\hline & Retained nipples & $\begin{array}{l}\text { Agreement with DA } \\
\text { prediction }\end{array}$ & \\
\hline & Sex organ weights & $\begin{array}{l}\text { Agreement with DA } \\
\text { prediction }\end{array}$ & \\
\hline & Hypospadia & $\begin{array}{l}\text { Synergism, effect exceeds } \\
\text { DA or IA prediction }\end{array}$ & \\
\hline \multirow[t]{2}{*}{$\begin{array}{l}\text { Epoxiconazole, mancozeb, } \\
\text { prochloraz, tebuconazole, } \\
\text { procymidone }\end{array}$} & Hypospadia & $\begin{array}{l}\text { Mixture induces higher } \\
\text { incidence than the most } \\
\text { potent component } \\
\text { (prochloraz) on its own }\end{array}$ & \multirow[t]{2}{*}{ Hass et al. 2012} \\
\hline & Retained nipples & $\begin{array}{l}\text { Agreement with DA } \\
\text { prediction }\end{array}$ & \\
\hline \multirow{5}{*}{$\begin{array}{l}\text { Vinclozolin, procymidone, } \\
\text { prochloraz, linuron, BBP, } \\
\text { DBP, DEHP }\end{array}$} & Shortened AGD & $\begin{array}{l}\text { Combined effect exceeded } \\
\text { DA and IA predictions }\end{array}$ & \multirow[t]{5}{*}{ Rider et al. 2008} \\
\hline & Retained nipples & $\begin{array}{l}\text { Combined effect exceeded } \\
\text { DA and IA predictions }\end{array}$ & \\
\hline & Hypospadia & $\begin{array}{l}\text { Combined effect exceeded } \\
\text { DA and IA predictions }\end{array}$ & \\
\hline & Cryptorchidism & $\begin{array}{l}\text { Combined effect exceeded } \\
\text { DA and IA predictions }\end{array}$ & \\
\hline & Epididymal agenesis & $\begin{array}{l}\text { Agreement with DA } \\
\text { prediction }\end{array}$ & \\
\hline \multirow{4}{*}{$\begin{array}{l}\text { Vinclozolin, procymidone, } \\
\text { prochloraz, linuron, BBP, } \\
\text { DBP, DEHP, DiBP, DiHeP, } \\
\text { DPeP }\end{array}$} & Hypospadia & $\begin{array}{l}\text { Agreement with DA } \\
\text { prediction }\end{array}$ & \multirow[t]{4}{*}{ Rider et al. 2010} \\
\hline & Epididymal agenesis & $\begin{array}{l}\text { Agreement with DA } \\
\text { prediction }\end{array}$ & \\
\hline & $\begin{array}{l}\text { Weights of sex accessory } \\
\text { organs }\end{array}$ & $\begin{array}{l}\text { Agreement with DA } \\
\text { prediction }\end{array}$ & \\
\hline & Cryptorchidism & $\begin{array}{l}\text { Combined effect falls short } \\
\text { of DA prediction }\end{array}$ & \\
\hline $\begin{array}{l}\text { DBP, DEHP, vinclozolin, } \\
\text { prochloraz, procymidone, } \\
\text { linuron, epoxiconazole, pp- } \\
\text { DDE, 4-MBC, OMC, } \\
\text { bisphenol A, butylparaben, } \\
\text { paracetamol }\end{array}$ & Retained nipples & $\begin{array}{l}\text { Effects of mixture were } \\
\text { greater than those of } \\
\text { paracetamol applied singly }\end{array}$ & Axelstad et al. 2014 \\
\hline $\begin{array}{l}\text { DBP, DEHP, vinclozolin, } \\
\text { prochloraz, procymidone, } \\
\text { linuron, epoxiconazole, pp- } \\
\text { DDE, 4-MBC, OMC, } \\
\text { bisphenol A, butylparaben, } \\
\text { paracetamol }\end{array}$ & $\begin{array}{l}\text { Reduced epididymal sperm } \\
\text { counts }\end{array}$ & $\begin{array}{l}\text { Effects of mixture were } \\
\text { similar to those of } \\
\text { paracetamol applied singly }\end{array}$ & Axelstad et al. 2018 \\
\hline
\end{tabular}

1 
In another study from the same lab, dose-response analyses of dibutyl phthalate (DBP) and prochloraz were conducted and their joint effects analysed in terms of agreement with predictions derived from DA and IA (Hotchkiss et al. 2010). With many of the endpoints examined in this study, the two concepts produced rather similar predictions of combined effects. For shortened AGD, retained nipples, reductions in prostate weight and epididymal agenesis, the observed combined effects of DBP and linuron agreed well with anticipated DA and IA additivity. With respect to incidences of hypospadias, the combined effects fell within the window defined by the DA and IA prediction curves. Due to the likeness of the DA- and IA-derived mixture effect predictions, it is difficult to come to definitive conclusions about similarity or dissimilarity of action in this case, although there was a tendency for DA to approximate the observed effects better than IA. This study substantiates the earlier findings from the experiments with BBP and linuron (Hotchkiss et al. 2004) and shows that activation of different MIE (prochloraz: AR antagonism, direct inhibition of steroidogenic enzymes, DBP: suppression of T synthesis by down-regulation of steroidogenic genes) leads to a convergence of pathways (key event 3, Figure 1) with cumulative effects on the male reproductive tract.

In an attempt to assess whether the diminished testicular $\mathrm{T}$ levels seen in the wake of administration of the HMG-CoA reductase inhibiting drug simvastin would produce cumulative effects with an agent that suppresses $\mathrm{T}$ synthesis differently via down-regulation of cholesterol transporters and steroidogenic enzymes, Beverly et al. (2014) combined simvastin and di-n-pentyl phthalate (DPP). The combination produced suppression of $T$ synthesis in foetal testes that exceeded the effects seen with simvastin or DPP on their own.

As already discussed, the mode of action of 2,3,7,8 TCDD in inducing lowered sperm counts is not through established anti-androgenic mechanisms. It was therefore of great interest to evaluate whether joint effects would materialise with an anti-androgen such as DBP. Strikingly, co-exposure to 2,3,7,8 TCDD exacerbated the incidence of epididymal and testicular malformations that are part of the typical effect spectrum of DBP (Rider et al. 2010). TCDD alone did not produce such malformations. There was also a cumulative effect on decreased epididymal sperm numbers. When combined at doses that individually did not lead to hypospadias, 2,3,7,8 TCDD and DBP together produced incidences in excess of $20 \%$.

Christiansen et al. (2009) evaluated the combined effects of diethyl-hexyl phthalate (DEHP), vinclozolin, finasteride and prochloraz. The observed mixture responses for shortened AGD, retained nipples, disrupted development of the ventral prostate and the leviator anus muscle agreed well with DA predictions. IA predicted somewhat lower effects in all cases. In contrast, the observed incidences of hypospadias by far exceeded what was anticipated by DA or IA. This could have been because the individual effects of some of the chemicals on hypospadias could not be measured in parallel with the mixture study, and instead had to be derived from historical data. This might have introduced systematic errors in calculating mixture effect predictions. In general, however, DA approximated the observed responses well, despite the fact that all mixture components act through distinctly different mechanisms involving a variety of MIE: DEHP by driving down T synthesis via gene expression modulations, vinclozolin by AR antagonism, finasteride by blocking the conversion of T to DHT and prochloraz by AR antagonism and direct inhibition of steroidogenic enzyme leading to lower $\mathrm{T}$ levels. Similar to the mixtures of BBP and linuron, and DBP and prochloraz, these pathways converge at the levels of decreased gene expression and protein synthesis in androgen-dependent tissues (key event 3 in Figure 1), which is a nodal point for malformations in reproductive tissues.

A mixture of epoxiconazole, mancozeb, prochloraz, tebuconazole, and procymidone produced retained nipples in male rat offspring (Hass et al. 2012). These effects were well approximated by the DA prediction. Due to missing dose-response data for some single mixture components, a prediction curve for hypospadias could not be constructed, but the mixture produced incidences far higher than those seen with prochloraz at the dose present in the combination. Many components in the mixture act through diverse mechanism already discussed. Epoxiconazole and tebuconazole affect foetal steroid hormone levels and mancozeb acts by disrupting the thyroid hormone system. 
Rider et al. (2008) examined a mixture composed of vinclozolin, procymidone, prochloraz, linuron, BBP, DBP and DEHP. In this study, the predicted combined effects were calculated based on historical dose-response data for the mixture components, which could have introduced systematic prediction errors. The combination produced multiple effects, including shortened AGD, retained nipples, hypospadias, cryptorchidisms, all at levels that exceeded the predictions derived from DA or IA. Of note, combination effects for hypospadias were not anticipated to occur according to IA. The degree of epididymal agenesis observed in the male offspring agreed well with the DA prediction. As with many of the mixtures already discussed, the pathways initiated by these agents converge in key event 3 , decreased gene expression and protein synthesis in androgen-dependent tissues.

Rider et al. (2010) used the same mixture as Rider et al. 2008, but added three further phthalates, di-npentyl phthalate (DPP), diisobutyl phthalate (DIBP) and diisoheptyl phthalate (DIHP). For hypospadias, epididymal agenesis and reduced weights of seminal vesicles, epididymis, ventral prostate and leviator anus muscle, the observed effects agreed well with the DA prediction, despite the wide variety of mechanisms involved in this mixture. The incidences of cryptorchidisms fell short of the DA prediction.

Axelstad et al. (2014) studied a mixture composed of DBP, DEHP, vinclozolin, prochloraz, procymidone, linuron, epoxiconazole, pp-DDE, 4-MBC, OMC, bisphenol A, butylparaben and paracetamol. This was a whole mixture experiment modelled on high end human exposures, not intended to test the predictive power of mixture assessment concepts or to examine the contribution of each component to the joint effect. However, paracetamol was tested on its own, at the dose present in the combination. This allows us to examine whether the other mixture constituents contributed to the effect of the analgesic. With paracetamol alone, 38\% of male offspring showed retained nipples, arguably due to the drug's ability of down-regulating steroidogenic genes. Administration of all 13 chemicals produced an incidence of $47 \%$, an effect attributable to DBP, DEHP, vinclozolin, prochloraz, procymidone, linuron, pp-DDE, butylparaben and bisphenol A, to varying degrees and by different mechanisms including AR antagonism. Paracetamol also suppressed epididymal sperm counts, 10 months after exposure had ended. The mixture produced similarly low sperm counts (Axelstad et al. 2018). Based on the AOP network in Figure 1, the various MIE triggered by components of this mixture will also have converged at key event 3 (decreased gene expression and protein synthesis in androgen-dependent tissues), with paracetamol likely contributing to the cumulative effect via down-regulation of steroidogenic genes.

Taken together, these studies provide strong evidence that cumulative effects can arise from multiple chemicals (including phthalates) that can trigger several independent converging pathways. How far down-stream these pathways must coalesce to achieve strict independence of effects is a matter of theoretical debate and cannot currently be resolved. In any case, none of the mixtures examined here complied with the principles of IA. This might have been expected in view of the activation of several different MIE. Instead, the studies by Christiansen et al. (2009) and Rider et al. (2010) provide good evidence that DA performed better in predicting the mixture effects. IA consistently underestimated the observed effects.

The experiments with combinations of 2,3,7,8 TCDD and DBP (Rider et al. 2010) even suggest that pathways converging at the level of adverse outcomes, rather than further up-stream at nodal points in the network, can also result in cumulative effects. This would be a case of strict independence of effects and strict dissimilarity of action. Further experiments involving combinations of phthalates and other anti-androgenic chemicals with dioxin-like pollutants are highly desirable to substantiate this issue.

Based on the experimental evidence currently available it is however difficult to say whether the pathway initiated by COX inhibition leading to reduced sperm production via disruption of the prostaglandin-mediated back-up mechanism for SOX9 activation can coalesce with the AR-dependent routes to produce cumulative effects. Future experiments e.g. with combinations of AR antagonists 
and agents capable of inhibiting COX enzymes, but without suppressing InsL3 synthesis (as paracetamol does), could resolve this point.

Finally, a case where coalescence of pathways has NOT led to cumulative down-stream effects could not be identified.

This review of experimental studies shows that AOP thinking is helpful in resolving the ambiguities that stem from differentiating the joint action of chemicals in terms of similarity or dissimilarity of action. Rather than deriving grouping criteria solely from mechanism of action considerations, it is more productive to place such considerations in the context of AOPs.

\section{Criteria for cumulative assessment groups for induction of male reproductive malformations}

Based on pathway considerations, and on empirically observed combination effects, cumulative assessment groups for male reproductive malformations should therefore - apart from phthalates comprise:

- AR antagonists,

- Agents capable of down-regulating cholesterol transporters and steroidogenic enzymes

- chemicals capable of directly inhibiting steroidogenic enzymes, or enzymes involved in cholesterol synthesis

- substances that down-regulate InsL3 synthesis,

- dioxin-like compounds, and

- COX inhibitors.

Thus, the chemicals to be added to phthalates cover a wide range of uses, including certain dicarboximide, azole and phenylurea pesticides, some phenolic compounds such as butylparaben and bisphenol A, pharmaceuticals including analgesics and lipid-lowering drugs, and dioxin-like pollutants. The list proposed in Figure 2 should be taken as a thought starter and is not intended to be exhaustive.

As a first step towards making more detailed decisions about candidate compounds, it is necessary to agree on the phthalates that should be included in the assessment group. Thus far, there has been no consistency in the phthalates included in recent mixture risk assessments. For example, Kranich et al. (2014) considered 4 phthalates, while the analysis by Hartmann et al. (2015) is based on 10 phthalates, including some with side chains of fewer than 4 carbons which do not induce antiandrogenic effects. The phthalates listed in Figure 2 would be suitable candidates.

\section{Figure 2: Some chemicals suggested for inclusion in a cumulative assessment group for male} reproductive malformations

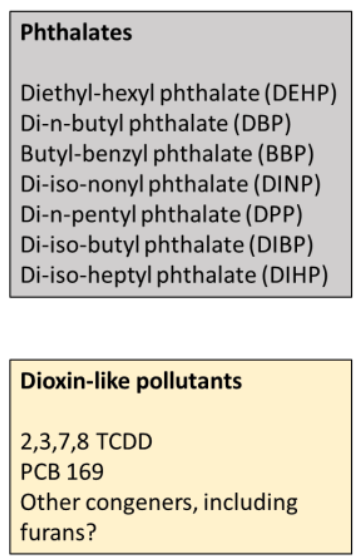

\begin{tabular}{|l|}
\hline \begin{tabular}{l} 
AR antagonists and inhibitors \\
of steroidogenic enzymes \\
Vinclozolin \\
Procymidone \\
Prochloraz \\
Bisphenol A \\
Linuron \\
Butylparaben \\
\hline Pain killers \\
Paracetamol \\
Aspirin \\
Ibuprofen \\
\hline Other pharmaceuticals \\
Finasteride \\
Ketoconazole \\
Simvastin
\end{tabular} \\
\hline
\end{tabular}


Next, a set of AR antagonists should be chosen, supported by data from in vivo studies. At a minimum, this should include vinclozolin, procymidone, prochloraz, butylparaben, bisphenol A and linuron. As data about the in vivo reproductive effects of other AR antagonists become available, these should also be added.

Among painkillers and other pharmaceuticals, paracetamol, aspirin, ibuprofen, finasteride, simvastin and ketoconazole should be included. Attention should be paid to other chemicals capable of activating suppression of prostaglandin synthesis in foetal life. There is in vitro data about a considerable number of such chemicals (Kristensen et al. 2011a; Kugathas et al. 2016). It remains to be seen which of these substances can disrupt male sexual differentiation in vivo.

Finally, inclusion of 2,3,7,8 TCDD and other dioxin-like pollutants deserves serious consideration. Health-based guidance values for these compounds are based on reductions of sperm counts and have recently been corrected down-wards by EFSA (EFSA 2018).

\section{Outlook and perspective}

The next step on the way to a mixture risk assessment for combined exposures to the substances listed in Figure 2 will be in compiling exposure data and potency values for endpoints relevant to male reproductive malformations. The phthalate mixture risk assessments published so far have used potency values for suppression of foetal $\mathrm{T}$ synthesis. Data for this endpoint are not always available for the other chemicals suggested for inclusion in the common assessment group. For some of the proposed chemicals such effects might not even materialise at all. Thus, it will be a major effort to select comparable potency values. Similar challenges can be expected in terms of availability of suitable exposure data and assessment of human relevance of data from animal experiments.

In conclusion, considerations of AOP networks have proven productive in deriving criteria for the grouping of phthalates and other chemicals in mixture risk assessments for male reproductive malformations. AOP thinking can help resolve the ambiguities that derive from ideas of similar and dissimilar action in mixture toxicology. 


\section{References}

Adams IR, McLaren A. (2002) Sexually dimorphic development of mouse primordial germ cells: Switching from oogenesis to spermatogenesis. Development 129(5), 1155-1164

Axelstad M, Christiansen S, Boberg J, Scholze M, Jacobsen PR, Isling LK, Kortenkamp A et al. (2014) Mixtures of endocrine-disrupting contaminants induce adverse developmental effects in preweaning rats. Reproduction, 147 (4), 1470-1626

Axelstad M, Hass U, Scholze M, Christiansen S, Kortenkamp A, Boberg J (2018) EDC IMPACT: Reduced sperm counts in rats exposed to human relevant mixtures of endocrine disrupters. Endocrine Connections 7 (1), 139 - 148

Beko G, Weschler CJ, Langer S et al. (2013) Children's phthalate intakes and resultant cumulative exposures estimated from urine compared with estimates from dust ingestion, inhalation and dermal absorption in their homes and day care centres. PLOS One 8 (4) e62442

Berkowitz GS, Lapinski RH. (1996) Risk factors for cryptorchidism: A nested case-control study. Paediatr Perinat Epidemiol 10 (1), 39-51

Beverly BEJ, Lambright CS, Furr JR et al. (2014) Simvastin and dipentyl phthalate lower ex vivo testicular testosterone production and exhibit additive effects on testicular testosterone and gene expression via distinct mechanistic pathways in the fetal rat. Toxicol Sci 141 (2), 524-537

Beverly BEJ, Furr JR, Lambright CS et al. (2019) In utero exposure to simvastin reduces postnatal survival and permanently alters reproductive tract development in the $\operatorname{Crl}: \mathrm{CD}(\mathrm{SD})$ male rat. Toxicol Appl Pharmacol 365, 112-123

Bliss CI (1939) The toxicity of poisons applied jointly. Annals of Applied Biology 26 (3), 585-615

Boisen KA, Chellakooty M, Schmidt IM, Kai CM, Damgaard IN, Suomi AM, et al. (2005) Hypospadias in a Cohort of 1072 Danish Newborn Boys: Prevalence and Relationship to Placental Weight, Anthropometrical Measurements at Birth, and Reproductive Hormone Levels at Three Months of Age. Journal of Clinical Endocrinology \& Metabolism 90, 4041-4046

Chang JW, LeeCC, Pan WH et al. (2017) Estimated daily intake and cumulative risk assessment of phthalates in the general Taiwanese after the 2011 DEHP food scandal. Sci Rep 7, 45009

Chia VM, Quraishi SM, Devesa SS, Purdue MP, Cook MB, McGlynn KA 2010 International Trends in the Incidence of Testicular Cancer, 1973-2002. Cancer Epidemiology Biomarkers \& Prevention 19, $1151-1159$

Christiansen S, Scholze M, Dalgaard M, Vinggaard AM, Axelstad M, Kortenkamp A, Hass U (2009) Synergistic disruption of external male sex organ development by a mixture of four antiandrogens. Environmental Health Perspectives 117, 1839-1846

Christiansen S, Kortenkamp A, Axelstad M, Boberg J, Scholze M, Jacobsen PR, Faust M, Lichtensteiger W, Schlumpf M, Burdorf A and Hass U (2012) Mixtures of endocrine disrupting contaminants modelled on human high-end exposures: An exploratory study in rats, International Journal of Andrology 35 (3), 303- 316

Christiansen S, Petersen MA, Boberg J, Vinggaard AM, Pedersen GA, Hass U (2014) Low dose effects of bisphenol A on early development in male and female rats. Reproduction, 147 (4), 477-487 

„,antiandrogenic“ chemicals at low individual doses produce reproductive tract malformations in the male rat, Toxicological Sciences 164, 166-178 (2018), available at https://doi: 10.1093/toxsci/kfy069

Dewalque L, Charlier C, Pirard C (2014) Estimated daily intake and cumulative risk assessment of phthalate diesters in a Belgian general population. Tox Lett 231, 161-168

Dong R, Zeng JH, Zhang MR et al. (2018) The concentration and cumulative risk assessment of phthalates in general population from Shanghai: The comparison between groups with different ages. Sci Total Environ 637-638, 871-880

Du P, Zhou Z, Huang H et al. (2018) Estimating population exposure to phthalate diesters in major Chinese cities through waste water based epidemiology. Sci Total Environ 643, 1602-1609

Ermler S, Scholze M, Kortenkamp A (2011) The suitability of concentration addition for predicting the effects of multi-component mixtures of up to 17 anti-androgens with varied structural features in an in vitro AR antagonist assay. Toxicol Appl Pharmacol 257 (2), 189-197

EFSA (European Food Safety Authority) (2008) Opinion of the Scientific Panel on Plant Protection Products and their Residues to evaluate the suitability of existing methodologies and, if appropriate, the identification of new approaches to assess cumulative and synergistic risks from pesticides to human health with a view to set MRLs for those pesticides in the frame of Regulation (EC) 396/2005. The EFSA Journal 2008, 704, 1-85

EFSA (European Food Safety Authority, (CONTAM Panel) (2018) Risk for animal and human health related to the presence of dioxins and dioxin-like PCBs in feed and food. EFSA Journal 16 (11), 5333

Foster WG, Maharaj-Briceno S, Cyr D (2010) Dioxin-induced changes in epididymal sperm count and spermatogenesis. Environ Health Perspect 118, 458-464

Gaudriault P, Mazaud-Guittot S, Lavoué V, Coiffec I, Lesné L, Dejucq-Rainsford N, Kortenkamp A et al. (2017) Endocrine Disruption in Human Fetal Testis Explants by Individual and Combined Exposures to Selected Pharmaceuticals, Pesticides, and Environmental Pollutants. Environmental Health Perspectives, 125 (8), 087004

Gray LE Jr, Kelce WR, Monosson E et al. (1995) Exposure to TCDD during development permananetly alters reproductive function in male Long Evans rats and hamsters. Tox Appl Pharmacol 131, 108-118

Gray LE Jr, Wilson V, Noriega N et al. (2004) Use of the laboratory rat as a model in endocrine disruptor screening and testing. ILAR Journal 45 (4), 425-437

Gupta C, Goldman AS (1986). The arachidonic acid cascade is involved in the masculinizing action of testosterone on embryonic external genitalia in mice. Proc Natl Acad Sci U S A 83 (12), 4346-4349

Gupta C, Bentlejewski CA (1992) Role of prostaglandins in the testosterone-dependent wolffian duct differentiation of the fetal mouse. Biol Reprod 47 (6), 1151-1160

Hartmann C, Uhl M, Weiss S et al. (2015) Human biomonitoring of phthalate exposures in Austrian children and adults and cumulative risk assessment. Int J Hygiene Env Health 218, 489-499

Hass U, Scholze M, Christiansen S, Dalgaard M, Vinggaard AM, Axelstad M, et al. (2007) Combined exposure to anti-androgens exacerbates disruption of sexual differentiation in the rat. Environ Health Perspect 115 Suppl:122-8 
Hass U, Boberg J, Christiansen S, Jacobsen PR, Vinggaard AM, Taxvig C, Poulsen ME, Herrmann SS, Jensen B H, Petersen A, et al. (2012) Adverse effects on sexual development in rat offspring after low dose exposure to a mixture of endocrine disrupting pesticides. Reprod. Toxicol. 34, 261-274

Hewlett PS, Plackett RL (1952) Similar joint action of insecticides. Nature, 169, 198-199

Howdeshell KL, Wilson VS, Furr J, Lambright CR, Rider CV, Blystone CR, et al. (2008) A mixture of five phthalate esters inhibits fetal testicular testosterone production in the sprague-dawley rat in a cumulative, dose-additive manner. Toxicological Sciences 105, 153-165

Howdeshell KL, Hotchkiss AK, Gray LE Jr (2017) Cumulative effects of antiandrogenic chemical mixtures and their relevance to human health risk assessment. Int J Hygiene Env Health 220, 179-188

Hotchkiss AK, Parks-Saldutti LG, Ostby JS, Lambright C, Furr J, Vandenbergh JG, Gray LE Jr. (2004) A mixture of the "antiandrogens" linuron and butyl benzyl phthalate alters sexual differentiation of the male rat in a cumulative fashion. Biol. Reprod. 71, 1852-1861

Hotchkiss AK, Rider CV, Furr J, Howdeshell KL, Blystone CR, Wilson VS, Gray LE Jr. (2010) In utero exposure to an AR antagonist plus an inhibitor of fetal testosterone synthesis induces cumulative effects on F1 male rats. Reprod. Toxicol. 30, 261-270

Isling LK, Boberg J, Jacobsen PR, Mandrup KR, Axelstad M, Christiansen S, et al. (2014) Late-life effects on rat reproductive system after developmental exposure to mixtures of endocrine disrupters. Reproduction, 147 (4), 465 - 476

Imperato-McGinley J, Sanchez RS, Spencer JR et al. (1992) Comparison of the effects of the 5alphareductase inhibitor finasteride and the antiandrogen flutamide on prostate and genital differentiation: Dose-response studies. Endocrinology 131 (3), 1149

Jensen MS, Rebordosa C, Thulstrup AM, Toft G, Sorensen HT, Bonde JP, Henriksen TB, Olsen J (2010) Maternal use of acetaminophen, ibuprofen, and acetylsalicylic acid during pregnancy and risk of cryptorchidism. Epidemiology 21, 779-785

Koopman P (2010) The delicate balance between male and female sex determining pathways: Potential for disruption of early steps in sexual development. Int J Androl 33 (2), 252-258

Kortenkamp A, Faust M (2010) Combined exposure to anti-androgenic chemicals: steps towards cumulative risk assessment. Int. J. Androl. 33, 463-472

Kortenkamp A, Faust M (2018) Regulate to reduce chemical mixture risk. Science 261 (6339), 4-6

Kranich SK, Frederiksen H, Andersson AM, Jorgensen N (2014) Estimated daily intake and hazard quotients and indices of phthalate diesters for young Danish men. Env Sci Technol 48, 706-712

Kristensen DM, Hass U, Lesn L, Lottrup G, Jacobsen PR, Desdoits-Lethimonier C et al. (2011a) Intrauterine exposure to mild analgesics is a risk factor for development of male reproductive disorders in human and rat. Human Reproduction 26 (1), 235-244

Kristensen DM, Skalkam ML, Audouze K, Lesné L, Desdoits-Lethimonier C, Frederiksen H et al. (2011b). Many putative endocrine disruptors inhibit prostaglandin synthesis. Environ Health Perspect 119 (4), 534-541

Kristensen DM, Mazaud-Guittot S, Gaudriault P, Lesné L, Serrano T, Main KM, et al. 2016. Analgesic use - prevalence, biomonitoring and endocrine and reproductive effects. Nat Rev Endocrinol 12, 381-393 
Kugathas S, Audouze K, Ermler S, Orton F, Rosivatz E, Scholze M , Kortenkamp A (2016) Effects of common pesticides on prostaglandin D2 (PGD2) inhibition in SC5 mouse sertoli cells, evidence of binding at the cox-2 active site, and implications for endocrine disruption. Environmental Health Perspectives, 124 (4), 452 - 459

Laier P, Metzdorff SB, Borch J, Hagen ML, Hass U, Christiansen S, et al. (2006) Mechanisms of action underlying the antiandrogenic effects of the fungicide prochloraz. Toxicol Appl Pharmacol $213,160-71$

Levine H, Jorgensen N, Martino-Andrade A et al. (2017) Temporal trends in sperm cunt: a systematic review and meta-regression analysis. Human Reprod Update 23 (6), 646-659

Lind JN, Tinker SC, Broussard CS, Reefhuis J, Carmichael SL, Honein MA, Olney RS, Parker SE, Werler MM. (2013) Maternal medication and herbal use and risk for hypospadias: data from the National Birth Defects Prevention Study, 1997-2007. Pharmacoepidemiol Drug Saf 22, 783-793

Loewe S, Muischnek H (1926) Über Kombinationswirkungen. Arch. für Exp. Pathol. und Pharmakologie 114, 313-326

Main KM, Skakkebaek NE, Virtanen HE, Toppari J (2010) Genital anomalies in boys and the environment. Best Practice Research Clinical Endocrinology Metabolism 24, 279-289

Mazaud-Guittot S, Nicholaz CN, Desdoit-Lethimonier C, Coiffec I, Ben Maamar M, Balaguer P, Kristensen DM, Chevrier C, Lavoue V, Poulain P, Dejucq-Rainsford N, Jegou B (2013) Paracetamol, aspirin and indomethacin induce endocrine disturbances in the human fetal testis capable of interfering with testicular descent. J Clin Endocrinol Metab 98, E1757-E1767.

Mitro SD, Johnson T, Zota AR (2015) Cumulative chemical exposures during pregnancy and early development. Curr. Environ. Health Rep. 2, 367-378

Moniot B, Declosmenil F, Barrionuevo F, Scherer G, Aritake K et al. (2009) The PGD2 pathway, independently of FGF9, amplifies SOX9 activity in Sertoli cells during male sexual differentiation. Development 136, 1813-1821

Nassar N, Bower C, Barker A (2007) Increasing prevalence of hypospadias in Western Australia, 1980-2000. Archives of Disease in Childhood 92, 580-584

Nelson CP, Park JM, Wan J, Bloom DA, Dunn RL, Wei JT (2005) The increasing incidence of congential penile anomolies in the United States. The Journal of Urology 174 (4, Part 2), 1573-1576

Orton F, Rosivatz E, Scholze M, Kortenkamp A (2012) Competitive androgen receptor antagonism as a factor determining the predictability of cumulative antiandrogenic effects of widely used pesticides. Environ Health Perspect 120 (11), 1578-1584

Orton F, Ermler S, Kugathas S, Rosivatz E, Scholze M, Kortenkamp A (2014) Mixture effects at very low doses with combinations of anti-androgenic pesticides, antioxidants, industrial pollutants and chemicals used in personal care products. Toxicol Appl Pharmacol 278 (3), 201-208

Pierik FH, Burdorf A, Nijman JMR, de Muinck Keizer-Schrama SMPF, Juttmann RE, Weber RFA (2002) A high hypospadias rate in The Netherlands. Human Reproduction 17, 1112-1115

Philibert P, Boizet-Bonhoure B, Bashamboo A, Paris F, Aritake K, Urade Y, Leger J, Sultan C, Poulat F (2013) Unilateral cryptorchidism in mice mutant for Ptgds. Human Mutation 34, 278-282

Philippat C, Giorgis-Allemand L, Chevrier C, Cordier S, Jegou B, Charles MA, Slama R (2012) Analgesics during pregnancy and undescended testis. Epidemiology 22 (5), 747-749 
Rider CV, Furr J, Wilson VS, Gray LE (2008) A mixture of seven antiandrogens induces reproductive malformations in rats. Int. J. Androl. 31, 249-262.

Rider CV, Furr JR, Wilson VS, Gray LE (2010) Cumulative effects of in utero administration of mixtures of reproductive toxicants that disrupt common target tissues via diverse mechanisms of toxicity. Int. J. Androl. 33, 443-462

Sharpe RM (2006) Pathways of endocrine disruption during male sexual differentiation and masculinisation. Best Pract Res Clin Endocrinol Metab 20, 91-110

Skakkebaek NE, Rajpert-De Meyts E \& Main KM (2001) Testicular dysgenesis syndrome: an increasingly common developmental disorder with environmental aspects. Apmis 109, S22-S28

Snijder CA, Kortenkamp A, Steegers EAP, Jaddoe VWV, Hofman A, Hass U et al. (2012) Intrauterine exposure to mild analgesics during pregnancy and the occurrence of cryptorchidism and hypospadia in the offspring: The generation R study. Human Reproduction 27 (4), 1191-1201

USNAS US National Academies of Science (2008) Phthalates and Cumulative Risk Assessment: The Task Ahead. National Academies Press, Washington, DC http://dels.nas.edu/dels/rpt briefs/phthalates final.pdf.

US EPA (2002) Guidance on cumulative risk assessment of pesticide chemicals that have a common mechanism of toxicity. In: Office of Pesticide Programs, Office of Prevention Pesticides and Toxic Substances. United States Environmental Protection Agency, Washington, DC, pp. 1-90 https://www.epa.gov/pesticide-science-and-assessing-pesticide-risks/guidance-cumulative-riskassessment-pesticide

van den Driesche S, Macdonald J, Anderson RA, Johnston ZC, Chetty T, Smith LB, et al. (2015) Prolonged exposure to acetaminophen reduces testosterone production by the human fetal testis in a xenograft model. Sci Transl Med 7, 288ra80

Wilhelm D, Mizusaki H, Widjaja L, Combes AN, Kanai Y, Koopman P (2007) SOX9 regulates prostaglandin D synthase gene transcription in vivo to ensure testis development. J Biol Chem 282 (14), 10553-10560

Wilson VS, Lambright CR, Furr JR et al. (2009) The herbicide linuron reduces testosterone production from the fetal rat testis during both in utero and in vitro exposures. Tox Lett 186, 73-77

Wolf C, Lambright C, Mann P et al. (1999) Administration of potentially antiandrogenic pesticides (procymidone, linuron, iprodione, chlozolinate, p, p-DDE, and ketoconazole) and toxic substances (dibutyl- and diethylhexyl phthalate, PCB 169, and ethane dimethane sulphonate) during sexual differentiation produces diverse profiles of reproductive malformations in the male rat. Tox Ind Health 15, 94-118 